\title{
THE ELECTRICAL CHARACTERISTICS OF LONG TRANSMISSION LINES WITH EXTERNAL FORCING IMPEDANCE
}

\author{
M. HAMED \\ Electrical Engineering Dept., Faculty of Engineering, Suez Canal University, \\ Port Said, Egypt.
}

(Received March 10, 1989; in final form June 20, 1989)

This paper presents a new idea for the radial type transmission line with external reactive forcing impedance at only the receiving end. The general constants of such line are deduced. The effect of both capacitive and inductive forcing impedances on the steady-state performance of the proposed line are studied. The maximum received power for a $1000 \mathrm{~km}$ line with capacitive forcing impedance is formulated. The rating of the suggested $1 \mathrm{k} \mathrm{Ohm}$ forcing capacitor for a $1000 \mathrm{~km}$ line is computed.

\section{INTRODUCTION}

In order to transmit AC electric power over a long distance, either series or shunt capacitive compensation is necessary. ${ }^{1}$ The power that can be transmitted on an uncompensated line decreases with increasing distance. ${ }^{2}$ For simplicity, this power may be expressed as a multiple of surge impedance loading.

If a special line should operate satisfactorily in the steady state, the transient behavior would be questionable and, by rapid control of voltage, the transient characteristics could be greatly improved. ${ }^{1}$ One of the earliest proposals for long distance AC large power transmission was presented in $1921 .^{3}$

The principal loss is in the resistance of the line conductors, while losses in the capacitive compensation are much lower and the active power losses may also be neglected. ${ }^{1}$

\section{PROBLEM FORMULATION}

Previous results for studies on coaxial lines ${ }^{4}$ were discouraging, as the value of maximum power limit over various lengths was very small. Results for 1000 to $1300 \mathrm{~km}$ radial lines ${ }^{5}$ were very encouraging. However, the steady state characteristics at open and short circuit conditions were not good. Also, the voltage difference between the conductors of the same phase was very high, precluding the practicability of the radial lines.

In order to improve these open and short circuit characteristics, it is desirable to insert a parallel impedance between the conductors of the same phase at only the line receiving end; the conductors of the same phase must not be connected at the sending end. This means that the proposed line is the radial transmission line ${ }^{5}$ but with external forcing impedance $\mathrm{Z}$ that will be connected between the conductors of the same phase at the receiving end as shown in Fig. 1. 


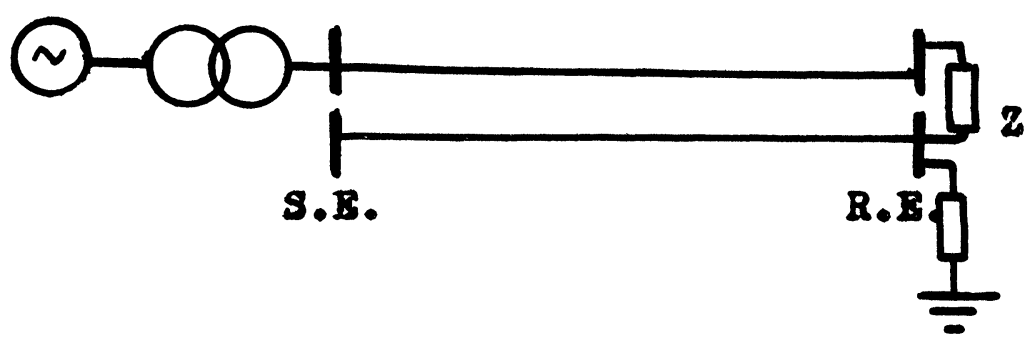

FIGURE 1 The single line diagram of the suggested line.

\section{THE GENERAL CONSTANTS}

For this type of lines (Fig. 1), the current $I_{z}$ through the impedance $Z$ can be found as

$I_{A}(1)=I_{z}=\frac{V_{A}(1)-V_{a}(1)}{Z}$

Using the method of ${ }^{4}$ the general equations of the receiving-end currents $I_{A}(1)$ and $I_{a}(1)$ and voltages $V_{A}(1)$ and $V_{a}(1)$ may be expressed in the final form:

$$
\begin{aligned}
& \mathrm{V}_{\mathrm{A}}(1)=\mathrm{V}_{\mathrm{g}} \cosh \mathrm{a}_{1} 1-\mathrm{Cn}_{7}-\mathrm{I}_{\mathrm{g}} \frac{\mathrm{m}_{1} \mathrm{n}_{3}}{\mathrm{~m}_{5}} \\
& \mathrm{~V}_{\mathrm{a}}(1)=\mathrm{K}_{1} \mathrm{~V}_{\mathrm{g}} \cosh \mathrm{a}_{1} 1+\mathrm{Cn}_{14}-\mathrm{I}_{\mathrm{g}} \frac{\mathrm{m}_{1} \mathrm{n}_{4}}{\mathrm{~m}_{5}} \\
& \mathrm{I}_{\mathrm{A}}(1)=\frac{-\mathrm{V}_{\mathrm{g}} \mathrm{K}_{4}}{\mathrm{~m}_{1}} \sinh \mathrm{a}_{1} 1+\frac{\mathrm{C} \mathrm{n}_{1}}{\mathrm{~m}_{1}}-\mathrm{I}_{\mathrm{g}} \frac{\mathrm{n}_{5}}{\mathrm{~m}_{5}} \\
& \mathrm{I}_{\mathrm{a}}(1)=\frac{-\mathrm{V}_{\mathrm{g}} \mathrm{K}_{5}}{\mathrm{~m}_{1}} \sinh \mathrm{a}_{1} 1+\frac{\mathrm{C} \mathrm{n}_{2}}{\mathrm{~m}_{1}}-\mathrm{I}_{\mathrm{g}}-\mathrm{I}_{\mathrm{g}} \frac{\mathrm{m}_{1} \mathrm{n}_{7}}{\mathrm{~m}_{5}}
\end{aligned}
$$

where the parameters $a_{1}$ and $a_{2}$ are forward and backward propagation coefficients of a line ${ }^{6}$ and $C, K_{1}$ and $K_{2}$ are the constants of integration. They may be evaluated using the terminal conditions, while all other parameters are given in appendix.

From Fig. 1 it is shown that the receiving end current $I_{R}$ must be equal to the sum of the two currents $I_{a}(1)$ and $I_{A}(1)$. Also, the general equations of the two port network may be introduced in the mathematical analysis.

The general constants of this type of lines using the same method that was given in $^{5}$ will be deduced in the form:

$$
\begin{aligned}
& A_{o}=\frac{-S_{1}+n_{11}-Z m_{5} m_{8}}{m_{5}\left(Z n_{1}+n_{10}\right)} \\
& B_{o}=\frac{m_{1}\left(Z\left(m_{2}+n_{13}\right)\right)-S_{8} n_{12}}{m_{5}\left(Z n_{1}+n_{10}\right)} \\
& C_{o}=\frac{-Z\left(m_{5} \sinh a_{1} 1 \sinh a_{2} 1\right)-n_{9}}{m_{1}\left(Z n_{1}+n_{10}\right)} \\
& D_{o}=\frac{-Z_{6}+S_{8} \cosh a_{1} 1 \cosh a_{2} 1}{\left(Z n_{1}+n_{10}\right)}
\end{aligned}
$$




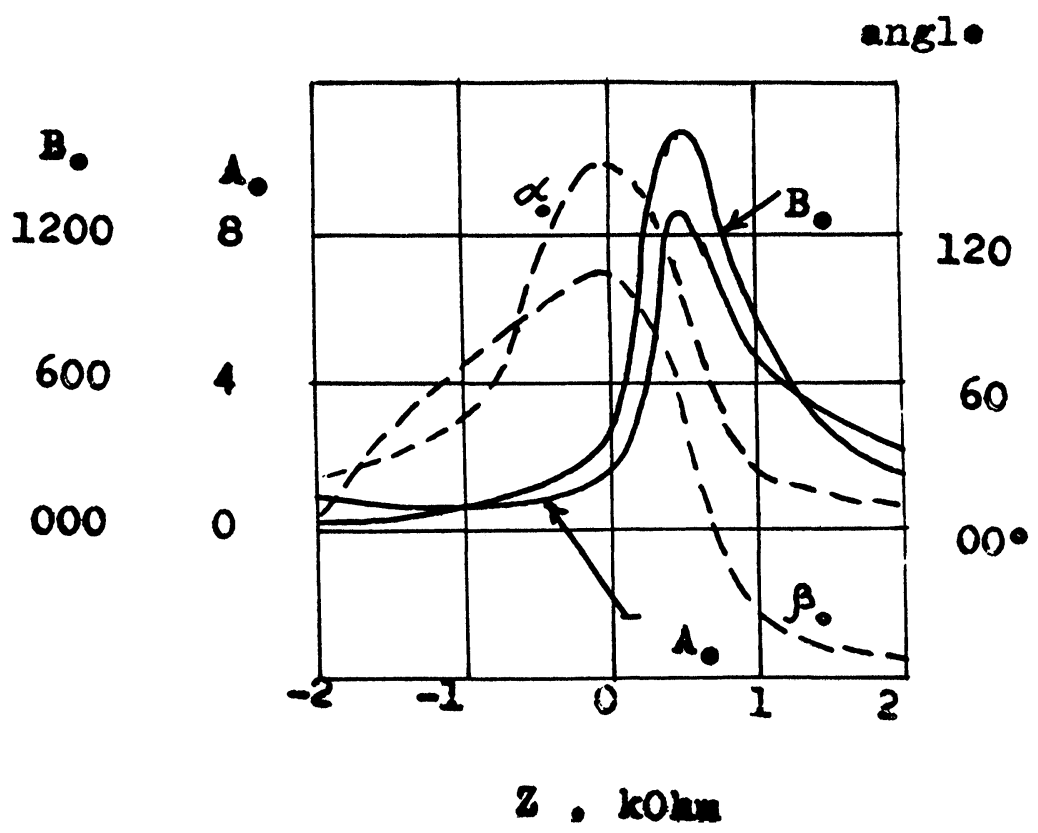

FIGURE 2 The general constants $A_{o}$ and $B_{o}$ of a $1000 \mathrm{~km}$ line.

Also, all values of the constants are given in the appendix.

The calculated general constants $A_{o}$ and $B_{o}$ are given in Fig. 2. The computed maximum received power for equal voltages at both sending and receiving ends of $220 \mathrm{kV}, 1000$ $\mathrm{km}$ line is shown in Fig. 3. The calculations are presented for different values of the forcing impedance.

When the reactance between the conductors is zero (they are solidly connected), the value of $\mathrm{A}_{\mathrm{o}}$ becomes greater than that for an ordinary line.

For the capacitive reactance the value of $A_{o}$ decreases, but as this reactance is increased, the line approaches the radial type and $A_{o}$ becomes the same value of the radial line.

If an inductive reactance is introduced, the value of the general constant $A_{o}$ rises, having a maximum at about $550 \mathrm{Ohms}$, then decreases again to the value of the radial line. ${ }^{5}$

The general constant $B_{o}$, when the forcing reactance is shorted, is comparable to that of an ordinary line. As the capacitive reactance is increased, it compensates for the line series impedance, decreasing the magnitude of the constant $B_{0}$.

Introducing an inductive forcing reactance increases the value of $B_{o}$ up to $500 \mathrm{ohms}$; above this the mutual effect through the air gap between the conductors comes in play and the value of $B_{o}$ approaches that for a radial line.

As either the inductive or capacitive reactance approaches infinity, the constants $A_{o}$ and $B_{o}$ should be the same for the radial line. The value for the inductive reactance is just opposite to that for capacitive reactance, since one case is minus infinity while the other is plus infinity. 


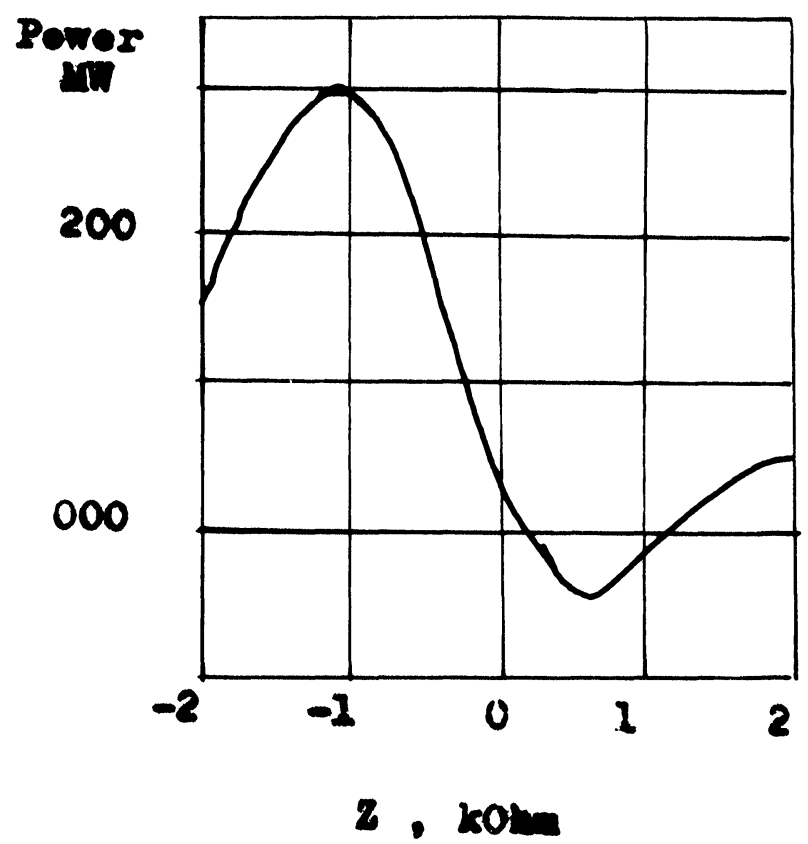

FIGURE 3 The maximum received power for a $1000 \mathrm{~km}$ line.

\section{POWER LIMIT}

Both capacitive and inductive reactances are considered to be connected between each phases of the two circuits of a line (A-a, B-b, C-c) at the receiving end. The reactive impedance is varied from $2 \mathrm{kohms}$ capacitive to $2 \mathrm{kohms}$ inductive. The results of this study are illustrated in Fig. 3. For the capacitive forcing reactance of $1 \mathrm{kohm}$, the power limit of a line is maximum. This optimal condition may occur because of the compensation of the series impedance of the main phase conductor, as reflected in the decrease of the line constant $B_{0}$. This constant means the series impedance of a line. ${ }^{6}$ The present case may have occured due to the increase of voltage difference between each two phases (Aa, B-b, C-c). Subsequently, the mutual cuopling between each two phases will be higher. However after a certain point, the increase of reactive power must be continued and the line may reach the condition of overcompensation. In this case the power transfer from one phase conductor to the other must be increased substantially, and the current through the external forcing capacitor will be reduced. This means that the maximum received power at the end of the studied line will be decreased.

On the other hand, the above investigated problem may lead to the case of maximum power limit; as the value of the external capacitive reactance becomes high, the mutual coupling between each two subsequent phases appears. So, the power limit reaches that value as deduced for the case of radial lines. ${ }^{5}$

When inductive reactance is added, the power decreases, becomes negative from 220 to $850 \mathrm{Ohms}$, and then becomes positive and approaches that value of the radial line. In this case, power transfer from the main conductor decreases, since the inductive reactance 
is increased. The mutual effect between the conductors increases, and so the power limit (which approaches the value of the radial line since the inductive reactance becomes considerably high), may be decreased.

It must be noted that the maximum received power with zero forcing impedance is less than that of an ordinary line of the same length.

\section{EXTERNAL CAPACITOR}

It is shown from Fig. 3 that the maximum received power occurs at $1 \mathrm{k}$ Ohm capacitive reactance. However, the practical possibility of this arrangement depends on the rating of this capacitor, which is required for the condition of the maximum transmitted power through the line. Therefore, it is necessary to determine the capacitor rating $S_{c}$ per phase, which will be:

$S_{c}=I_{z}\left(V_{A}(1)-V_{a}(1)\right)$

The results of calculations show that the power limit for $1 \mathrm{kohm}$ capacitive forcing reactance is as high as $300 \mathrm{MW}$, and the capacitor rating is $715 \mathrm{MW}$ per phase (where the voltage across it and current through it are $500 \mathrm{kV}$ and $500 \mathrm{kA}$ respectively). These values are very high and the practical possibility of the line still requires more investigation. The transferred power from one conductor of the proposed line to the other is $169 \mathrm{MW}$ instead of $130 \mathrm{MW}$ for the radial line [5]. The current throught the capacitor at even unity power factor is 440 A with the rating of 570 MVA.

The sending-end phase voltage of conductor a is 1.9 times the voltage $\mathrm{V}_{\mathrm{g}}$ and the voltage difference between the conductors of the same phase at the receiving end is no better than the values for the radial line. Different spacings or distribution of the capacitance between the conductors of the same phase along the line might give better characteristics.

\section{CONCLUSIONS}

The power limit for the studied long transmission lines can be increased by installing an external capacitive impedance between both circuits at the receiving end of a line.

The connection of external forcing inductor between circuits of the suggested type of transmission lines give poor line performance, so that such connections must be removed.

The installed external forcing capacitance between circuits of the investigated lines modify the line characteristics.

The proposed capacitor should not be installed only at the receiving end but it should be distributed along the overall line length.

The maximum received power of a $1000 \mathrm{~km}$ line with an external capacitor of $1 \mathrm{kohm}$ is more realistic, leading to the practical possibility of the application of extra lons transmission lines. 
The nominal transmission voltage must be increased for the best condition of transferred and transmitted powers.

\section{REFERENCES}

1. E.W. Kimbark: A new look at shunt compensation. IEEE Trans., Vol. PAS-102, No. 1, pp. 212-218 (1983).

2. Dunlop, R.D., Gutman, R., and P.P. Marchenko: An anlylical development of loadability characteristics for EHV and UHV transmission lines. IEEE Trans., Vol. PAS-98, No. 2, pp. 606-617 (1979).

3. F.G. Baum: Voltage regulation and insulation for large-power long-distance transmission systems. AIEE Trans., Vol. 40, pp. 1018-1077 (1921).

4. Hamed, M., S.S.El-Desseuky: The coaxial transmission line performance. Proc. of the 27th Midwest Symposium on Circuits \& Systems, Morgantown, USA, June 11-12, pp. 338-340 (1984).

5. M. Hamed: The steady state characteristics of the radial type transmission line. Proc. of JIEEEC' 85,28 April-1 May, Amman, Jordan, pp. 425-429 (1985).

6. M. Hamed: Similarity criteria of EHF physical model of long distance transmission line with plate phases. Active and Passive Electronic Components, 1988. 


\section{APPENDIX: MATHEMATICAL EXPRESSIONS OF PARAMETERS}

$$
\begin{aligned}
& \mathrm{n}_{1}=\mathrm{K}_{4} \sinh \mathrm{a}_{1} 1-\mathrm{K}_{3} \sinh \mathrm{a}_{2} 1 \\
& \mathrm{n}_{2}=\mathrm{K}_{5} \sinh \mathrm{a}_{1} 1-\mathrm{K}_{6} \sinh \mathrm{a}_{2} 1 \\
& \mathrm{n}_{3}=K_{5} \sinh \mathrm{a}_{2} 1-K_{6} \sinh \mathrm{a}_{1} 1 \\
& \mathrm{n}_{4}=\mathrm{K}_{2} \mathrm{~K}_{5} \sinh \mathrm{a}_{2} 1-\mathrm{K}_{1} \mathrm{~K}_{6} \sinh \mathrm{a}_{1} 1 \\
& \mathrm{n}_{5}=\mathrm{K}_{4} \mathrm{~K}_{6} \cosh \mathrm{a}_{1} 1-\mathrm{K}_{3} \mathrm{~K}_{5} \cosh \mathrm{a}_{2} 1 \\
& \mathrm{n}_{6}=\mathrm{m}_{6} \sinh \mathrm{a}_{2} 1 \cosh \mathrm{a}_{1} 1-\mathrm{m}_{7} \sinh \mathrm{a}_{1} 1 \cosh \mathrm{a}_{2} 1 \\
& \mathrm{n}_{7}=\cosh \mathrm{a}_{1} 1-\cosh \mathrm{a}_{2} 1 \\
& \mathrm{n}_{8}=\mathrm{K}_{5} \sinh \mathrm{a}_{1} 1 \cosh \mathrm{a}_{2} 1-\mathrm{K}_{6} \sinh \mathrm{a}_{2} 1 \cosh \mathrm{a}_{1} 1 \\
& \mathrm{n}_{9}=\mathrm{S}_{6} \sinh \mathrm{a}_{1} 1 \cosh \mathrm{a}_{2} 1+\mathrm{S}_{7} \cosh \mathrm{a}_{1} 1 \sinh \mathrm{a}_{2} 1 \\
& n_{10}=S_{5} \cosh a_{1} 1-S_{4} \cosh a_{2} 1 \\
& \mathrm{n}_{11}=\mathrm{S}_{3} \cosh \mathrm{a}_{1} 1 \cosh \mathrm{a}_{2} 1-\mathrm{S}_{2} \sinh \mathrm{a}_{1} 1 \sinh \mathrm{a}_{2} 1 \\
& \mathrm{n}_{12}=\mathrm{K}_{6} \sinh \mathrm{a}_{1} 1 \cosh \mathrm{a}_{2} 1-\mathrm{K}_{5} \sinh \mathrm{a}_{2} 1 \cosh \mathrm{a}_{1} 1 \\
& n_{13}=m_{4} \sinh a_{1} 1 \sinh a_{2} 1-m_{3} \cosh a_{1} 1 \cosh a_{2} 1 \\
& \mathrm{n}_{14}=\mathrm{K}_{2} \cosh \mathrm{a}_{2} 1-\mathrm{K}_{1} \cosh \mathrm{a}_{1} 1 \\
& \mathrm{~S}_{1}=\mathrm{m}_{1}\left(\mathrm{~K}_{3} \mathrm{~K}_{5}\left(1-\mathrm{K}_{2}\right)+\mathrm{K}_{4} \mathrm{~K}_{6}\left(1-\mathrm{K}_{1}\right)\right. \\
& \left.+\mathrm{K}_{5} \mathrm{~K}_{6}\left(2-\mathrm{K}_{1}-\mathrm{K}_{2}\right)\right) \\
& \mathrm{S}_{2}=\mathrm{m}_{1}\left(\mathrm{~K}_{4} \mathrm{~K}_{5}\left(1-\mathrm{K}_{2}\right)+\mathrm{K}_{3} \mathrm{~K}_{6}\left(1-\mathrm{K}_{6}\right)\right. \\
& \left.+\mathrm{K}_{5}^{2}\left(1-\mathrm{K}_{2}\right)+\mathrm{K}_{6}^{2}\left(1-\mathrm{K}_{1}\right)\right) \\
& \mathrm{S}_{3}=\mathrm{m}_{1}\left(\mathrm{~K}_{5} \mathrm{~K}_{6}\left(2-\mathrm{K}_{1}-\mathrm{K}_{2}\right)+\mathrm{K}_{3} \mathrm{~K}_{5}\left(1-\mathrm{K}_{1}\right)\right. \\
& \left.+\mathrm{K}_{4} \mathrm{~K}_{6}\left(1-\mathrm{K}_{2}\right)\right) \\
& \mathrm{S}_{4}=\mathrm{m}_{1}\left(1-\mathrm{K}_{2}\right) \\
& \mathrm{S}_{5}=\mathrm{m}_{1}\left(1-\mathrm{K}_{1}\right) \\
& \mathrm{S}_{6}=\mathrm{m}_{1}\left(1-\mathrm{K}_{2}\right)\left(\mathrm{K}_{4}+\mathrm{K}_{5}\right) \\
& \mathrm{S}_{7}=\mathrm{m}_{1}\left(1-\mathrm{K}_{1}\right)\left(\mathrm{K}_{3}+\mathrm{K}_{6}\right) \\
& \mathrm{S}_{8}=\mathrm{m}_{1}\left(\mathrm{~K}_{2}-\mathrm{K}_{1}\right)
\end{aligned}
$$



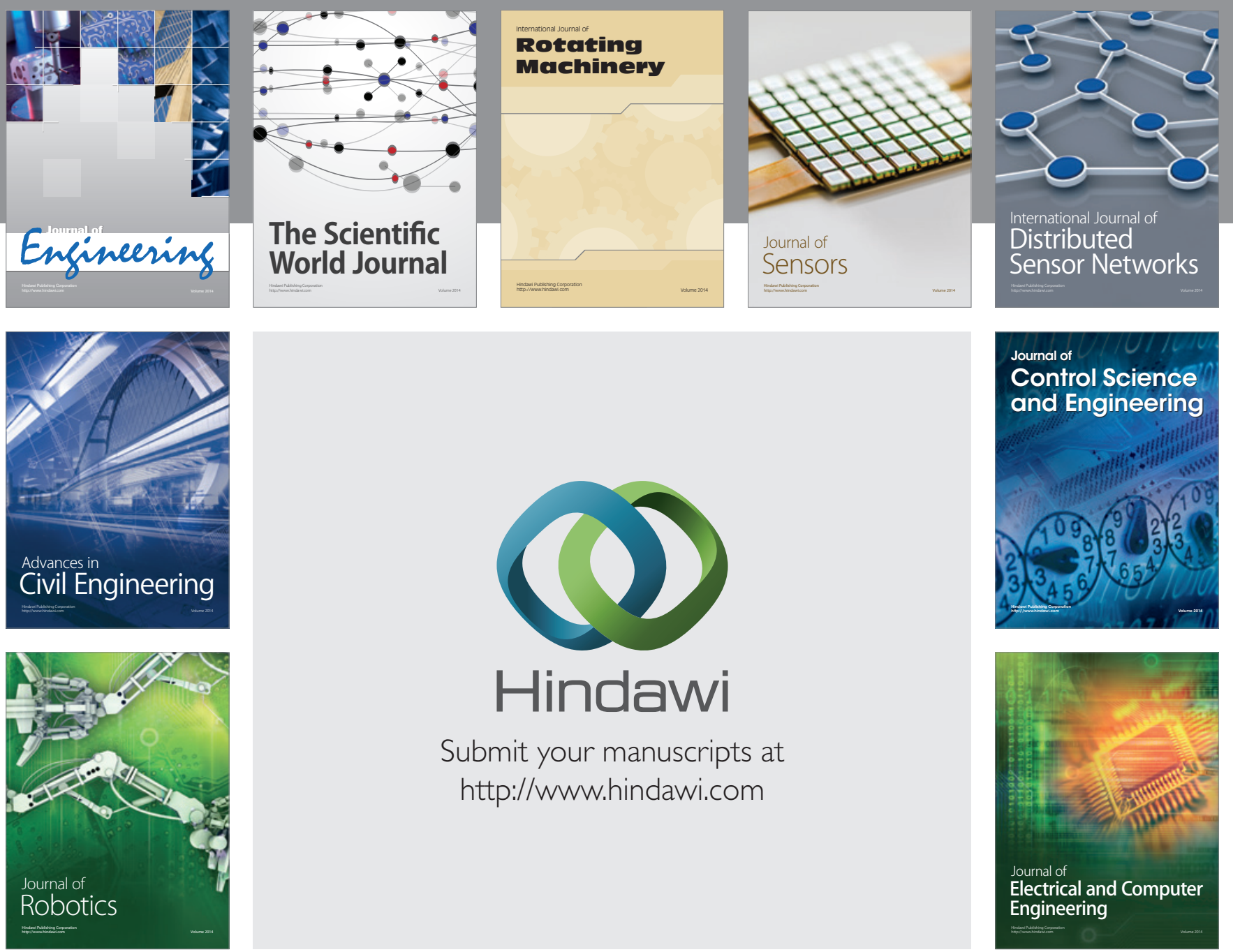

Submit your manuscripts at

http://www.hindawi.com
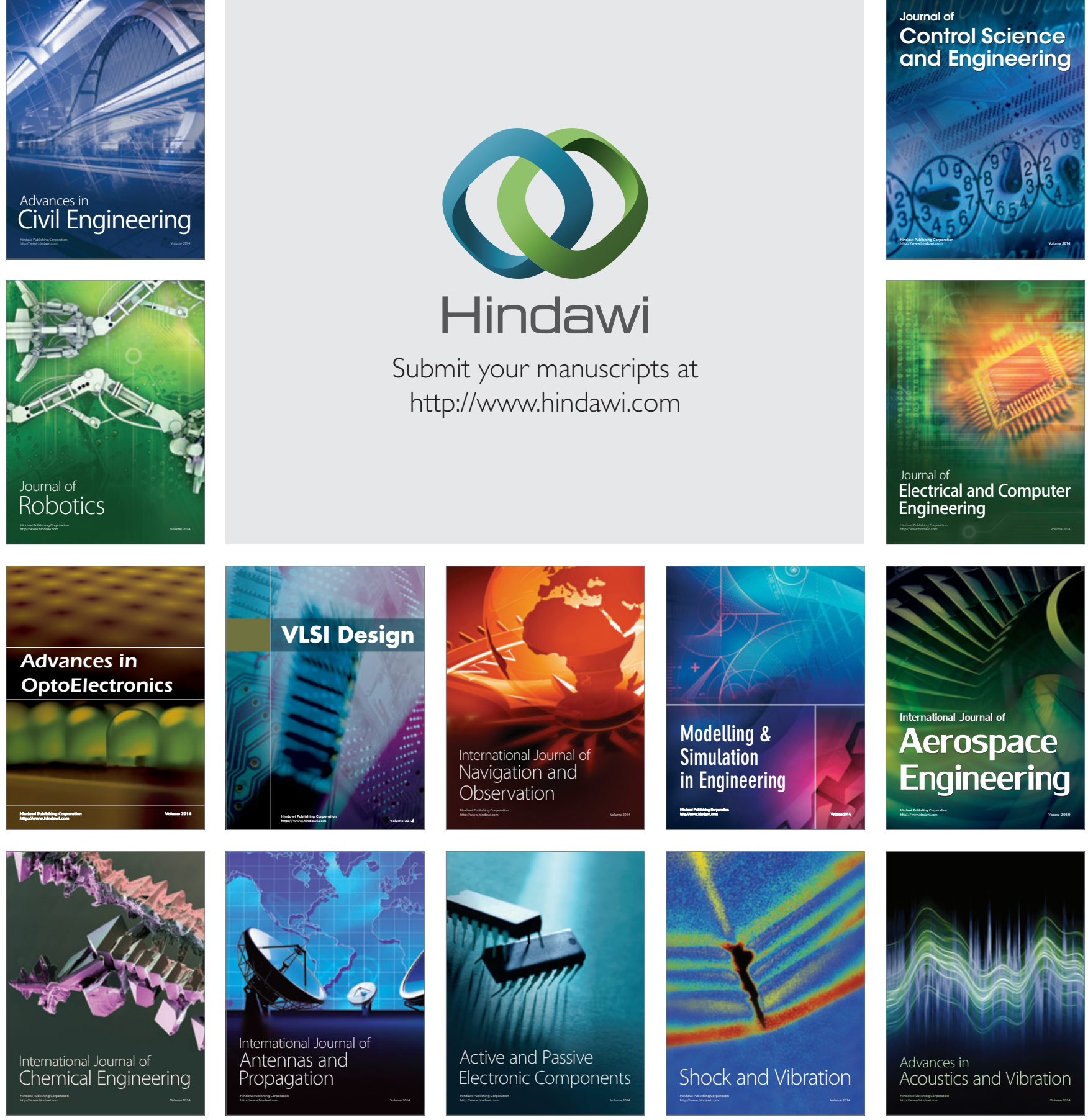